\title{
PSICODRAMA PEDAGÓGICO: ESTRATÉGIA PARA O ENSINO EM ENFERMAGEM
}

\author{
PEDAGOGICAL PSYCH ODRAM A: NURSIN G TEACHING STRATEGY \\ PSICODRAM A PEDAGÓGICO: ESTRATEGIA PARA LA ENSEÑ ANZA \\ DE ENFERMERÍA
}

\section{ADRIANA KATIA CORRÊA*, MARIA CONCEIÇÃO BERNARDO DE MELLO E SOUZA*, TOYOKO SAEKI*}

\begin{abstract}
RESUMEN
El contexto actual de la enseñanza de graduación en la enfermería brasileña apunta a la necesidad de repensar la formación profesional, incluyendo cambios curricularescon énfasis en la articulación teórico-práctica y en estrategias de enseñanza activas con enfoque vivencial, buscando una actuación crítica, humana y creativa. Cabe destacar que el Informe para la UNESCO de la Comisión Internacional sobre la Educación para el Siglo XXI (Delors, 2001) indica cuatro pilares básicos esenciales orientadores dela política educacional de todos los países: aprender a conocer, aprender a vivir juntos, aprender a hacer y aprender a ser. La propuesta de este estudio es reflexionar sobre el uso del psicodrama pedagógico como estrategia para la enseñanza en enfermería. El psicodrama aplicado a la educación posibilita el desarrollo de la espontaneidad, creatividad y sensibilidad necesarias para el ejercicio del trabajo grupal, involucrando la comprensión de las relaciones humanas. Lo cotidiano en salud demanda que el profesional movilice recursos y conocimientos para reconocer las singularidades delas situaciones, lo que se relaciona con el desarrollo de la espontaneidad y la creatividad.
\end{abstract}

Palabras claves: Psicodrama pedagógico, enseñanza, enfermería.

\begin{abstract}
The current context of Brazilian undergraduate nursing teaching points out the need to reconsider professional education, involving curricular changes with an emphasis on the articulation between theory and practice and on active teaching strategies that focus on experiences, with a view to a critical, humane and creative performance. It should be highlighted that the International Commission's Report for UNESCO on education for the XXIts century (Delors, 2001) indicates four essential basic pillars to guide educational policies in all countries: learning to know, learning to live together, learning to do and learning to be. This study aims to reflect on the use of pedagogical psychodrama as a strategy for nursing teaching. The application of psychodrama to education allows for the development of the necessary spontaneity, creativity and sensibility for group work exercises, involving the understanding of human relations. Day-to-day work in the health sector requires professionals to mobilize resources and knowledge to recognize the particularities of each situation, which is related to the development of spontaneity and creativity.
\end{abstract}

Keywords: Pedagogical Psychodrama, Teaching, Nursing.

Recepcionado: 19.01.2004. Aceptado: 30.08.2004.

\section{INTRODUCCIÓN}

En Brasil los cursos de graduación del área de salud están siendo reestructuradosconsiderando las nuevas directrices curriculares (2001) reglamentadas por el M inistério da Educação/ Conselho Nacional de Educação, orientadas por la Lei de Diretrizes e Bases da Educação Nacional de 1996.

Además, las reestructuraciones curricula-

\footnotetext{
* Enfermeira, Profesor Doutor da Escola deEnfermagem deRibeirao Preto da Universidad deSao Paulo, Centro Colaborador para o Desenvolvimento da Pesquisa em Emfermagem da Organizacao M undial de Saúde/O rganizacao Panamericana de Saúde. Avenida Bandeirantes 3900 - CEP 14040-902 - Rebeirao Preto - SP - Brasil. E-mail: adricor@eerp.usp.br
} 
res emergen como importantes, considerando la necesidad de inversiones para la consolidación del Sistema Ú nico de Saúde (SUS), que se basa en principios como la integridad de la atención, lo que exige una mirada ampliada sobreel proceso salud-enfermedad más allá del eje biológico, así como la competencia para el trabajo interdisciplinario.

Actualmente, el Ministério da Saúde(2003) propone una política de educación permanente que también incluye la reformulación de los currículos de los cursos de bachillerato, con la intención dearticular mejor la educación con el mundo del trabajo, fortaleciendo el compromiso de la universidad con la cotidianidad de los servicios de salud.

Las directrices curriculares enfatizan que la formación profesional no se restrinja sólo a la competencia técnica, sino que contemple también las competencias políticas, éticas y humanas.

Se espera que los proyectos político-pedagógicos de los cursos del área de la salud contemplen algunos principios:

- Currículos fundamentados en metodologías activas.

- Integración de contenidos básicos y profesionalizantes.

- Relación de equilibrio entre teoría y práctica.

- Diversificación de los escenarios de aprendizaje.

- Educación orientada a los problemas más relevantes de la sociedad.

- Currículos flexibles.

- Educación centradaen el alumno, visto como sujeto de los procesos deenseñanza y aprendizaje.

- Evaluación formativa del alumno, basada en las competencias cognitivas, afectivas y psicomotoras (Rede Unida, 1999).

Estos principios revelan la necesidad de sobrepasar la enseñanza tradicional, teniendo en vista sus límites. La enseñanza tradicional está centrada en la figura del profesor y el alumno es considerado un mero receptor pasivo deinformaciones, teniendo poca oportunidad de desarrollar la iniciativa y el sentido crítico.

En ese contexto, la enseñanza de graduación en la enfermería brasileña apunta también a la necesidad de repensar la formación profesional, incluyendo cambios curriculares con énfasis en la articulación teórico-práctica y en estrategias de enseñanza activas con enfoque vivencial, buscando una actuación crítica, humana y creativa que responda a las demandas de los servicios, teniendo en vista la complejidad del trabajo en salud.

Es evidentequelaformación predominantementetécnica y basada en la dimensión biológica es insuficiente para constituir acciones de salud que contemplen la construcción de calidad devida. Por eso la importancia de invertir en un proceso formativo basado en la visión del alumno en su integridad, trascendiendo el eje técnico.

Cabe destacar que el Informe para la UNESCO de la Comisión Internacional sobre la Educación para el Siglo XXI (Delors, 2001) indica cuatro pilares básicos esenciales orientadores de la política educacional de todos los países: aprender a conocer, aprender a vivir juntos, aprender a hacer y aprender a ser.

A prender a conocer serefierea adquirir los instrumentos decomprensión; aprender avivir juntos se relaciona a participar y cooperar con los otros en todas las actividades humanas; aprender a hacer en la búsqueda de ser actuante y actuar sobre el medio, y aprender a ser como vía esencial que integra las precedentes.

La construcción de un proceso formativo basado en esos pilares implica posicionamientosfilosófico y político y la búsqueda deotros referentes de enseñanza-aprendizaje.

Comprendemos que uno de los referentes que puede apoyar ese proceso formativo es el psicodrama pedagógico quevaloriza el aprendizaje vivencial, integrando el pensar, el sentir y el actuar. 
La propuesta deeste estudio es reflexionar sobreel uso del psicodrama pedagógico como estrategia para la enseñanza en enfermería.

\section{EI PSICODRAMA PEDAGÓGICO EN LA EN SEÑANZA DE ENFERMERÍA}

Comúnmente, en la relación enseñanza aprendizaje, el mundo es teorizado constituyéndoseen una abstracción dela realidad. Sin embargo, el alumno viveen una realidad concreta einmediata que se muestra, muchas veces, confusa y contradictoria. Por eso la necesidad del educador deconciliar la transmisión deconocimientossistemáticos-que promuevan la comprensión del mundo y de las posibilidades y límites del hombre con la necesidad de facilitarle al alumno el reconocimiento de su realidad, favoreciendo el desarrollo de su comprensión critica y activa y su voluntad transformadora. Para ello, es preciso integrar conocimiento adquirido y experiencia vivida (Romaña, 1985).

Tal integración, sin embargo, se pierde en el enfoque de la enseñanza tradicional que valoriza la acumulación y la reproducción de conocimientos adquiridos en detrimento de la creación de nuevos modos de pensar, sentir y actuar.

M oreno (1993), destacando la declinación de la función creadora del hombre, comenta que el problema consiste en sustituir un sistema de valores ya desgastado y obsoleto, por él denominado "conserva cultural", por otro sistema deval ores queresponda a las circunstancias de nuestra época: el complejo espontaneidad-creatividad.

Comenta Moreno (1993, p. 197) que a medida que el alumno va progresando en sus estudios académicos, de la escuela a la universidad, las implicaciones psicodramáticas del proceso educacional se van disipando; “(...) el resultado es un adolescente confuso en su espontaneidad y un adulto privado de ella (...)".
Lo cotidiano en salud demanda queel profesional movilice recursos y conocimientos para reconocer las singularidades de las situaciones, lo que se relaciona con el desarrollo de la espontaneidad y creatividad.

En el área de la salud, específicamente en enfermería, el alumno es preparado para una actividad práctica que exige otros abordajes de enseñanza queno se limiten sólo a la apropiación teórica de conceptos ni al hacer desprovisto de reflexión y sensibilidad, sino que posibiliten una perspectiva para su hacer, tomando distancia para analizar sus acciones y crear nuevas alternativas adecuadas a las situaciones ya vividas. En ese proceso, el discente puede ampliar su repertorio, transformándose, así como su práctica en el contexto de salud.

Como hemos comentado, cuidar del otro en la perspectiva de la calidad de vida implica unaformación quetambién considereal alumno en su integridad, articulando las dimensiones cognitivas, afectivas y psicomotoras que están estrechamente superpuestas.

El psicodrama pedagógico puede favore cer dicha formación al privilegiar el aprendizaje vivencial, con vistas a despertar el complejo espontaneidad-creatividad, imprescindible para enfrentar las situaciones cotidianas.

El psicodrama aplicado a la educación se refierea la utilización sistematizada dela dramatización de temas en el aula. No es sólo la teatralización de asuntos de las disciplinas curriculares, sino una secuencia de eventos que propician la espontaneidad necesaria para crear y construir conocimiento. Los alumnos, trabajando en grupo, sesocializan, seintegran, descubren sus límites y los de los otros, elaborando conceptos y de este modo, (inter) actuando (Rosinha, 1999).

Relatando una experiencia de implementación de un currículo integrado de una escuela de enfermería en una universidad pública brasileña, las autoras describen cambios en la enseñanza en salud mental: al contrario 
de lidiar con el otro a partir de la enfermedad, proponen tener como referencia el yo, enfocando que la comprensión de sí mismo esfundamental para la comprensión del otro. A partir del contacto consigo mismo, del descubrimiento de su subjetividad, el alumno puede desarrollar la sensibilidad para la escucha y la recepción del otro. Así, va construyendo su conocimiento y no sólo absorbiendo lo queestá en los libros (Rochaet al., 2003).

Pensamos que este modo de enseñar debe ser ampliado a otras áreas de conocimiento, considerando quela subjetividad está presente en todo espacio y proceso enseñanza-aprendizaje.

Cabe resaltar que el alumno, muchas veces, se enfrenta con situaciones que despiertan sentimientos y conflictos que necesitan ser elaborados para poder responder efectivamentealas demandas provenientes dela atención a los pacientes y de las relaciones entre los profesionales, quevan más allá de las normas instituidas.

El psicodrama pedagógico se presta, así, a un aprendizaje diferente del tradicional, privilegiando la vivencia y produciendo resultados que permanecen con los participantes por mucho tiempo, al involucrar el pensar, el sentir y el actuar (Datner, 1999).

Pensar sobre estas cuestiones nos lleva a reflexionar sobre la formación docente y cuánto el espacio académico necesita abrirse para cambiosen el proceso enseñanza-aprendizaje. Creemos que este es un camino a ser construido, lo que supone " (...) superar la visión estrecha que reduce la educación a la escolarización y esta a la enseñanza-aprendizaje - dominio de competencias, habilidades y técnicas de intervención. Educación, en la tradición más permanente y fecunda, encuentra su sentido como trato pedagógico de los complejos y delicados procesos de humanización. Y también como cuidado. Educar es humanizar. Cuidar es, también, humanizar. Es acompañar al ser humano desde la infancia en las artes deaprender a ser persona. Decons- truirse y formarse como persona" (Arroyo, 2003, p. 70).

\section{CONSIDERACIONES FINALES}

El psicodrama pedagógico puede ser una estrategia que posibilite la formación integral del docenteen enfermería, articulando teoría y práctica, y las dimensiones racional y afectiva que están presentes en el proceso enseñanza-aprendizaje.

Al entrar en contacto con el otro y consigo mismo, el alumno se inquieta, cuestionando las "conservas culturales" del mundo del trabajo en salud y de la propia formación, pudiendo desarrollar la sensibilidad y la capacidad crítica para comprender y transformar la realidad.

Proponer innovaciones, en el contexto académico, no involucra solamentela utilización de nuevas técnicas de enseñanza, sino implicareflexionar sobrelosfundamentos del proceso enseñanza-aprendizaje, considerando nuestra intencionalidad expresa en el acto de educar: ¿educamos para la creación y transformación o sólo para la conservación de lo instituido?

\section{REFERENCIAS BIBLIOGRÁFICAS}

ARROYO, G.M . (2003). Escola e trabalho: desafios e oportunidades na construção de uma política pública deformação profissional em saúde. In: Fórum Nacional do PROFAE: construindo uma política de formação em saúde, 1, Brasília, 2002. Relatório Geral. Brasília, M inistério da Saúde, 2003, pp. 6480.

CONSELHO NACIONAL DE EDUCAÇÃO (2001). Câmara de Educação Superior. Resolucão CNE/ CES. Diretrizes Curriculares Nacionais do Curso de Graduacão em Enfermagem. 7 de novembro.

DELORS, J. et al. (1998). Educação: um tesouro a descobrir. Relatório U NESCO. São Paulo, CORTEZ. M INISTÉRIO DA SAÚ DE (2003). Política de educação e desenvolvimento para o SUS/Caminhos para a educação permanente em saúde/Pólos de educação permanente em saúde.Secretaria de Gestão do 
Trabalho e da Educação na Saúde, Departamento de Gestão e da Educação na Saúde, Brasília.

M OREN O, J.L. (1993). Psi codrama. São Paulo, Cutrix. REDE UNIDA (1999). Contribuicão para as novas diretrizes curriculares dos cursos de graduacão da área de saúde. Olho Mágico, v. 5, n. especial, novembro.
ROSINHA, M .U. (1999).Renovacão didática na universidadeatravés do psicodrama. Rev. Brasileira dePsicodrama, v. 7, n. 1.

ROM AÑ A, M .A. (1985).Psicodrama Pedagógico: mé todo educacional psicodramático. Campinas, Papirus. 